\title{
Docetaxel in the treatment of non-small cell lung carcinoma: an update and analysis
}

\author{
This article was published in the following Dove Press journal: \\ Lung Cancer:Targets and Therapy \\ 15 June 2010 \\ Number of times this article has been viewed
}

\author{
Matthew A Gubens \\ Heather A Wakelee \\ Department of Medicine, Division \\ of Oncology, Stanford University \\ School of Medicine, Stanford, CA, USA
}

\begin{abstract}
Docetaxel, a semisynthetic taxane, was the first agent to show efficacy in the second-line treatment of non-small cell lung cancer (NSCLC), and has since become a mainstay of NSCLC therapy. We review its mode of action, pharmacology, toxicity and efficacy and describe both its established role in the treatment of NSCLC and future directions in research. Docetaxel works primarily by promoting microtubule assembly and polymerization, and through this hyperstabilization, causes cell cycle arrest and death. The primary toxicity of docetaxel is neutropenia, which can be mitigated by weekly administration in selected patients. Less common toxicities are peripheral edema, which can be reduced by appropriate premedication and interstitial pneumonitis. Hypersensitivity reactions are less frequent than with paclitaxel. Docetaxel has shown a survival and quality of life advantage as a single agent first- and second-line versus placebo, as well as first-line in a platinum-based doublet therapy compared to a single agent. Increasingly docetaxel has also been used effectively in adjuvant regimens in earlier stages of the disease. Future areas of research include combinations with novel targeted therapies, and a greater understanding of biomarkers that might help predict efficacy and personalize therapy.
\end{abstract}

Keywords: Docetaxel, taxanes, non-small cell lung carcinoma, review, metastatic, adjuvant

\section{Introduction}

Lung cancer continues to be the most common cause of cancer-related morbidity, leading to an estimated 159,840 deaths in the United States in 2009 alone. ${ }^{1}$ Among incident lung cancer cases in the US, about $85 \%$ are non-small cell lung cancer (NSCLC). Unfortunately, only approximately $30 \%$ of NSCLC is detected at an early, resectable stage, and nearly half of patients present with metastatic disease. ${ }^{2}$ Even a substantial portion of the patients that are diagnosed at the earlier stages progress and will require systemic therapy.

The mainstay of therapy for over 15 years in stage IV or inoperable stage III cancer has been a platinum doublet (ie, either cisplatin or carboplatin in combination with a second chemotherapeutic agent), initiated at the time of diagnosis as first-line therapy. Until the introduction of the semisynthetic taxane docetaxel (Taxotere ${ }^{\circledR}$; sanofi-aventis, Paris, France), no treatment had been shown in randomized clinical trials to improve survival or quality of life in the second-line treatment of advanced or metastatic NSCLC. Since its approval for this indication, docetaxel has also been approved for use in the first-line setting, either alone or in combination with a platinum agent and has been investigated for earlier stages of disease and in a variety of combinations with novel agents as well. Although other chemotherapy agents with utility in this clinical niche
Correspondence: Heather A Wakelee Stanford Cancer Center, Stanford University School of Medicine, 875 Blake Wilbur Dr, Rm 2233 MC 5826, Stanford, CA 94305 USA

Tel +l 6507239094

Fax +I 6507243697

Email hwakelee@stanford.edu 
have since been introduced, docetaxel remains a mainstay of the NSCLC therapy.

This paper will discuss the pharmacology of docetaxel and its toxicity profile. The clinical efficacy of docetaxel will then be reviewed in various clinical scenarios with an emphasis on phase III and notable phase II studies. We will briefly review the significance of patient-related outcome data associated with docetaxel, and will then conclude with a discussion of selected trials currently underway.

\section{Pharmacology}

Docetaxel is a member of the taxane family that includes paclitaxel. Whereas paclitaxel is the active ingredient of the bark of the Pacific Yew tree, Taxus brevifolia, docetaxel is a semi-synthetic combination formed by the esterification of a noncytotoxic precursor extracted from the needles of the European yew, Taxus baccata. ${ }^{3}$ An early advantage of the drug was the more widespread availability (and ability for regeneration) of this different yew species, ${ }^{4}$ but over time some relative clinical advantages of docetaxel over paclitaxel have emerged.

Like paclitaxel, docetaxel promotes microtubule assembly and polymerization. By stabilizing the growing microtubule, the drug disrupts the equilibrium between tubulin formation and breakdown, ultimately leading to the impairment of mitosis and then cell cycle arrest. ${ }^{4}$ Docetaxel is twice as potent as paclitaxel in its ability to inhibit depolymerization, and cross resistance between taxanes is incomplete, with the second-line activity of docetaxel documented in patients previously treated with paclitaxel. ${ }^{5}$ For example, in the pivotal TAX 320 study of second-line docetaxel versus vinorelbine or ifosfamide after a platinum doublet, a subgroup analysis was performed of patients who had previously been treated with paclitaxel. Among patients on the docetaxel arm, there was no difference in efficacy or survival between the patients who had previously progressed on paclitaxel and those who had never previously been exposed to a taxane. ${ }^{6}$

The taxanes may also work by other mechanisms. They may directly influence apoptosis pathways, and the higher potency docetaxel exhibits in phosphorylating bcl-2, compared to paclitaxel, may explain its stronger proapoptotic activity. ${ }^{7}$ Docetaxel also has some antiangiogenic effect that has been demonstrated both in vitro and in vivo to a greater extent than paclitaxel. ${ }^{7}$ Though less well understood, aside from their antimitotic properties, taxanes also appear to induce proinflammatory genes and proteins, including tumor necrosis factor- $\alpha$, various interleukins and enzymes such as nitric oxide synthase and cycloocygenase-2, and though it is unclear what role this may play in its tumor cytotoxic effect, ${ }^{8}$ there is a suggestion this upregulation may play a role in the hypersensitivity reactions experienced by patients. ${ }^{7}$

\section{Toxicity}

The primary dose-limiting toxicity in early studies of docetaxel was neutropenia, and even at the therapeutic doses given in current practice, neutropenia persists as a frequent toxicity effect. ${ }^{3}$ A systematic review of studies enrolling a total of 1609 patients reported a pooled estimate of febrile neutropenia incidence of about $6 \% .{ }^{9}$ Another meta-analysis reported that weekly dosing led to a reduction of grade 3 and 4 neutropenia (18\% versus $5 \%, P<0.0001)$ and febrile neutropenia $(6 \%$ versus $<1 \%, P<0.0001) .{ }^{10}$ Low grade anemia is noted in a large majority of patients treated with docetaxel, but less than $10 \%$ have grade 3 or above anemia. This is not significantly different in weekly dosing.

Though a weekly schedule confers less neutropenia, it is associated with significantly elevated rates of epiphora, or excessive tearing. While more frequently noted in trials of docetaxel in breast cancer patients than in NSCLC, this toxicity can occasionally be dose-limiting. Prompt symptom control is critical with ocular moisturizers or even short course ophthalmologic steroids. ${ }^{11}$

Another toxicity more commonly seen with docetaxel than with paclitaxel is peripheral edema, typically starting with the lower extremities. Use of a dexamethasone premedication regimen of $8 \mathrm{mg}$ by mouth, twice daily, the day before, the day of, and the day after treatment with docetaxel can significantly reduce the incidence of edema.

Though hypersensitivity reactions are less common in patients receiving docetaxel compared with paclitaxel, they have been observed, and may be related to the Polysorbate 80 in which the drug is dissolved. ${ }^{12}$ It is thought that the above dexamethasone protocol may also help prevent hypersensitivity reactions.

Less common grade 3 and grade 4 toxicities include interstitial pneumonitis, which is related to both type I and type IV hypersensitivity reactions, and which may be increased in the setting of concomitant treatments such as gemcitabine. ${ }^{13}$ Asthenia can be seen in as many as $18 \%$ of patients, although this is more common in the elderly. Common grades 1 and 2 toxicities associated with docetaxel include fatigue, nausea and vomiting, stomatitis and alopecia, but these do not typically worsen to grade 3. Nail dystrophy is also a common toxicity, which can lead to superinfection. ${ }^{14}$ Neurotoxicity has 
been noted infrequently, including paresthesias and dysesthesisas, though typically in grade 1 or 2 .

\section{Metabolism and drug-drug interactions}

Docetaxel is metabolized extensively by the cytochrome P450 CYP system, with CYP3A representing the major route of inactivation. Other chemotherapeutics used in NSCLC do not appear to impair the clearance of docetaxel. Though the potential interactions between antiepileptic drugs and docetaxel have not been formally studied, they may reduce the effectiveness of docetaxel through increased clearance given they are powerful inducers of CYP3A4. Conversely, ketoconazole, a strong inhibitor of CYP3A, results in decreased docetaxel clearance. ${ }^{15}$

Docetaxel is primarily excreted through feces and bile, and must be dose reduced in the setting of hepatic impairment. However, the product insert directs the drug not be given when bilirubin is above the upper limit of normal, or when transaminases are above 1.5 times the upper limit of normal when alkaline phosphatase is more than 2.5 times the upper limit of normal. Docetaxel has minimal renal excretion and thus renal impairment does not preclude use of docetaxel. ${ }^{16}$

\section{Efficacy}

Docetaxel was first approved by the US Food and Drug Administration (FDA) in 1996 for use in metastatic breast cancer, but shortly thereafter garnered indications for first and second-line use in NSCLC. Below we review all the phase III trials involving docetaxel in the treatment of lung cancer, with selected references to pertinent phase II trials. Tables 1 and 2 summarize the efficacy data from the phase III trials, in advanced and metastatic disease, in the first and second line, respectively. Also we briefly describe efforts to study the use of docetaxel in earlier stages of the disease to complement chemoradiation and surgical modalities of treatment.

\section{First-line use of docetaxel in advanced and metastatic NSCLC}

The American Society of Clinical Oncology (ASCO) and most other oncology organizations endorse combination therapy for first-line use in most advanced stage NSCLC patients. ${ }^{17}$ Typically these regimens consist of platinum chemotherapy doublets, and docetaxel is a frequently utilized component in these doublets as discussed below. However, for the elderly and those with a poor performance status combination regimens are rarely well tolerated and in such patients single chemotherapeutics, including docetaxel, can be considered. ${ }^{17}$

\section{Docetaxel as single agent}

A seminal phase III study in advanced stage NSCLC reported by Roszkowski and colleagues in 2000 showed the superiority of docetaxel over best supportive care (BSC), increasing survival from 5.7 to 6.0 months, and 1-year survival from $16 \%$ to $25 \%(P=0.04)$. Response and quality of life (QoL) were also superior in the docetaxel arm. ${ }^{18}$ Notably, the study used a dose of $100 \mathrm{mg} / \mathrm{m}^{2}$, which is now disfavored when compared to $75 \mathrm{mg} / \mathrm{m}^{2}$ which gives a more favorable toxicity profile without any sacrifice of clinical efficacy, as demonstrated by the TAX 317 and 320 studies described below in the section on second-line treatment section.

WJTOG 9904, another phase III study, compared docetaxel at $60 \mathrm{mg} / \mathrm{m}^{2}$ with vinorelbine in an elderly population over the age of 70 in Japan, and demonstrated a statistically significant improvement in response $(22.7 \%$ versus $9.9 \%, P=0.019)$, and a trend towards improved survival in patients treated with docetaxel (14.3 versus 9.9 months, hazard ratio $0.78, P=0.065$ ). This finding was of particular relevance given the concern for poor tolerability of combination regimens in the elderly demographic. ${ }^{19}$

\section{Docetaxel in combination with a platinum agent}

Several phase III studies have evaluated use of docetaxel as a component of a platinum doublet with either cisplatin or carboplatin. Georgoulias and colleagues compared a cisplatin/docetaxel doublet to docetaxel alone, using a dose of $100 \mathrm{mg} / \mathrm{m}^{2}$ in both, and finding with the doublet an improved response rate $(36.5 \%$ versus $21.1 \%, P=0.004)$, though only a trend toward improved survival $(10.5$ versus 8.0 months, $P=0.020){ }^{20}$

Several studies have compared docetaxel-containing doublets to other doublets, with most making use of what has become the standard dose of docetaxel in doublet regimens, $75 \mathrm{mg} / \mathrm{m}^{2}$. The large TAX 326 trial compared either cisplatin or carboplatin plus docetaxel with cisplatin plus vinorelbine as a control. This study showed improved response and survival with the cisplatin plus docetaxel regimen as compared to the cisplatin plus vinorelbine arm (31.6\% versus $24.5 \%$, $P=0.029$ and 11.3 versus 10.1 months, $P=0.044$ ). However, there was no significant difference between the control arm and the carboplatin plus docetaxel arm, indicating better efficacy with use of cisplatin. ${ }^{21}$ These findings were confirmed in a subgroup analysis of patients over the age of $65 .{ }^{22}$ 
Table I Phase III trials of docetaxel used first-line in advanced or metastatic NSCLC

\begin{tabular}{|c|c|c|c|c|c|}
\hline Trial and reference & Regimen & $\mathbf{N}$ & RR (\%) & MST (months) & I year OS (\%) \\
\hline \multirow[t]{2}{*}{ Roszkowski' } & - Doce $100 \mathrm{dl} q 3 \mathrm{w}$ & 207 & $13.1 *$ & $6.0 *$ & $25^{*}$ \\
\hline & - Best supportive care & & 0 & 5.7 & 16 \\
\hline WJTOG 9904 & In elderly $>70$ & & & & \\
\hline \multirow[t]{2}{*}{ Kudoh $^{19}$} & - Doce $60 \mathrm{dl}$ q3w & 182 & $22.7 *$ & 14.3 & 58.6 \\
\hline & $-\operatorname{Vin} 25 \mathrm{dl}+8 \mathrm{q} 3 \mathrm{w}$ & & 9.9 & 9.9 & 36.7 \\
\hline \multirow[t]{2}{*}{ Georgoulias $^{20}$} & - Doce $100 \mathrm{dl}+$ cis $80 \mathrm{~d} 2 \mathrm{q} 3 \mathrm{w}$ & 319 & $36.5^{*}$ & 10.5 & 44 \\
\hline & - Doce $100 \mathrm{dl} q 3 \mathrm{w}$ & & 21.2 & 8.0 & 43 \\
\hline TAX 326 & - Doce 75 + cis 75 dl q3w & 1218 & $31.6 *$ & $11.3^{*}$ & $46^{*}$ \\
\hline \multirow[t]{2}{*}{ Fossella $a^{21}$} & - Doce 75 + carbo AUC 6 dl q3w & & 23.9 & 9.4 & 38 \\
\hline & -Vin $25 \mathrm{dl} / 8 / 15 / 22+$ cis $100 \mathrm{dl} q 4 \mathrm{w}$ & & 24.5 & 10.1 & 41 \\
\hline \multirow[t]{2}{*}{ TAX 326 elderly only } & In elderly $>65$ & & & & \\
\hline & - Doce $75+$ cis $75 \mathrm{dl}$ q3w & 401 & NR & $12.6 *$ & $52^{*}$ \\
\hline \multirow[t]{2}{*}{ Belani $^{22}$} & - Doce 75 + carbo AUC $6 \mathrm{dl}$ q3w & & & 9 & 38 \\
\hline & $\begin{array}{l}- \text { Vin } 25 \mathrm{dl} / 8 / / 5 / 22+\text { cis } \\
\quad 100 \mathrm{dl} \mathrm{q} 4 \mathrm{w}\end{array}$ & & & 9.9 & 41 \\
\hline \multirow[t]{2}{*}{ Kubota $^{23}$} & - Doce $60+$ cis $80 \mathrm{dl}$ q3 or $4 w$ & 311 & $37.1^{*}$ & $11.3^{*}$ & $47.7^{*}$ \\
\hline & - Cis $80 \mathrm{dl}+$ vindesine $\mathrm{dl} / 8 / 15 \mathrm{q} 4 \mathrm{w}$ & & 21.2 & 9.6 & 24.4 \\
\hline GLOB 3 & - Doce $75+$ cis $75 \mathrm{dl} \mathrm{q3w}$ & 390 & 27.2 & 9.8 & 40.9 \\
\hline \multirow[t]{2}{*}{$\operatorname{Tan}^{24}$} & - Cis $80 \mathrm{dl}+$ vin IV $30 \mathrm{dl}+$ vin PO $80 \mathrm{~d} 8$ & & 27.4 & 9.9 & 39.4 \\
\hline & q3w (first cycle IV 25 and oral 60) & & & & \\
\hline \multirow[t]{4}{*}{ Booton 25} & - Doce 75 + carbo AUC 6 dl q3w & 433 & 67 & 9.5 & 39 \\
\hline & - Choice of & & 65 & 8.7 & 35 \\
\hline & Mito $6+$ ifos $3+$ cis $50 \mathrm{dl}$ q3w & & & & \\
\hline & Mito $6+$ vinblastine $6+$ cis $50 \mathrm{dl} \mathrm{q} 3 \mathrm{w}$ & & & & \\
\hline \multirow[t]{5}{*}{ Schiller ${ }^{26}$} & - Cis $75+$ doce $75 q 3 w$ & 1155 & 17 & 7.4 & 31 \\
\hline & - Cis $75 \mathrm{~d} 2+$ paclitaxel I $35 \mathrm{dl}$ q3w & & 21 & 7.8 & 31 \\
\hline & - Cis $75 \mathrm{dl}+$ gem & & 22 & 8.1 & 36 \\
\hline & $1000 \mathrm{dl} / 8 / 15 \mathrm{q} 3 \mathrm{w}$ & & & & \\
\hline & - Carbo AUC 6 + paclitaxel 225 q3w & & 17 & 8.1 & 34 \\
\hline \multirow[t]{4}{*}{ Kubota ${ }^{31}$} & - Vin $25 \mathrm{dl}+$ gem & 401 & $25^{*}$ & 13.6 & 57.1 \\
\hline & $1000 \mathrm{dl} / 8 \mathrm{q} 3 \mathrm{w} \times 3$ & & & & \\
\hline & then doce $60 \mathrm{dl} q 3 \mathrm{w} \times 3$ & & 37 & 14.1 & 56.5 \\
\hline & - Carbo AUC $6+$ pac 225 dl q3w $\times 6$ & & & & \\
\hline \multirow[t]{3}{*}{ Georgoulias 32} & - Doce $100 \mathrm{~d} 8+$ gem & 413 & 30 & 9.0 & 34.3 \\
\hline & $1000 \mathrm{dl} / 8 \mathrm{q} 3 \mathrm{w}$ & & & & \\
\hline & - Cis $80 \mathrm{~d} 8+\operatorname{vin} 30 \mathrm{dl} / 8 \mathrm{q} 3 \mathrm{w}$ & & 39.2 & 9.7 & 40.8 \\
\hline \multirow[t]{2}{*}{ Pujol $^{33}$} & - Doce $85 \mathrm{~d} 8+$ gem $1000 \mathrm{dl} / 8 \mathrm{q} 3 \mathrm{w}$ & 311 & 31 & II.I & 46 \\
\hline & $-C$ is $100 \mathrm{dl}+\operatorname{vin} 30 \mathrm{dI} / 8 / 15 / 22 \mathrm{q} 4 \mathrm{w}$ & & 35.9 & 9.6 & 42 \\
\hline \multirow[t]{2}{*}{ Georgoulias $^{34}$} & - Doce $100 \mathrm{dl}$ q3w & 312 & $11.6 *$ & $8.3^{*}$ & 35.5 \\
\hline & - Doce 75 d8 + gem II 100 dI/8 q3w & & 26.8 & 9.4 & 41.4 \\
\hline \multirow[t]{3}{*}{ Hainsworth ${ }^{35}$} & In elderly $>65$ & & & & \\
\hline & - Doce $35 \mathrm{dl} / 8 / \mathrm{I} 5 \mathrm{q} 4 \mathrm{w}$ & 350 & 17 & 5.1 & 24 \\
\hline & - Doce $30+$ gem $800 \mathrm{dl} / 8 / 15 \mathrm{q} 4 \mathrm{w}$ & & 25 & 5.5 & 26 \\
\hline \multirow[t]{5}{*}{ Cobo ${ }^{36}$} & - Doce $75+$ cis 75 dl q3w & 444 & $37.6 *$ & 9.8 & 39.0 \\
\hline & - Selection based on ERCCI level & & 47.2 & 9.9 & 40.4 \\
\hline & - Low: doce $75+$ cis $75 \mathrm{dl}$ q3w & & 53.2 & 10.4 & 44.0 \\
\hline & - High: doce $40+$ gem & & 47.2 & 9.5 & 33.0 \\
\hline & $1000 \mathrm{dl} / 8 \mathrm{q} 3 \mathrm{w}$ & & & & \\
\hline BMS-099 & - Doce 75 or paclitaxel $225+$ carbo & 676 & $25.7 *$ & NR & NR \\
\hline \multirow[t]{3}{*}{ Lynch $^{39}$} & $\begin{array}{l}\text { AUC } 6 \mathrm{dl} \text { q3w + cetuximab } 400 \text {, } \\
\text { then } 250 \mathrm{qlw}\end{array}$ & & & & \\
\hline & - Doce 75 or paclitaxel $225+$ carbo & & 17.2 & & \\
\hline & AUC $6 \mathrm{dl} \mathrm{q} 3 \mathrm{w}$ & & & & \\
\hline
\end{tabular}

Notes: *denotes statistically significant result. All doses in milligrams per meter squared $\left(\mathrm{mg} / \mathrm{m}^{2}\right)$ except as noted.

Abbreviations: N, number of subjects; RR, response rate; MST, median survival time; OS, overall survival; Doce, docetaxel; q3w, every 3 weeks; Vin, vinblastine; Cis, cisplatin; Carbo, carboplatin; AUC, area under the curve; NR, not reported; PO, oral; IV, intravenous; Ifos, ifosfamide; Mito, mitomycin; Gem, gemcitabine. 
Table 2 Phase III trials of docetaxel used second-line in advanced or metastatic NSCLC

\begin{tabular}{|c|c|c|c|c|c|}
\hline $\begin{array}{l}\text { Trial and } \\
\text { reference }\end{array}$ & Regimen & $\mathbf{N}$ & $\mathbf{R R}$ & MST & I year OS \\
\hline TAX 317 & - Doce 75 q3w & 204 & 7 & $7.5^{*}$ & $37 *$ \\
\hline \multirow[t]{2}{*}{ Shepherd ${ }^{41}$} & - Doce 100 q3w & & 7 & 5.9 & 19 \\
\hline & - Best supportive care & & 0 & 4.6 & 19 \\
\hline TAX 320 & - Doce $100 \mathrm{dl}$ q3w & 373 & $10.8^{*}$ & 5.5 & 21 \\
\hline \multirow[t]{2}{*}{ Fossella $^{6}$} & - Doce 75 dl q3w & & $6.7^{*}$ & 5.7 & $32 *$ \\
\hline & - Vin or ifos & & 0.8 & 5.6 & 19 \\
\hline \multirow[t]{2}{*}{$\operatorname{Ramlau}^{43}$} & - Doce $75 \mathrm{dl}$ q3w & 829 & 4 & $3 I w$ & 29 \\
\hline & - Oral topotecan $2.3 \mathrm{dI}-5 \mathrm{q} 3 \mathrm{w}$ & & 5 & $28 w$ & 25 \\
\hline STELLAR I & - Doce $75 \mathrm{dl}$ q3w & 849 & 12 & 6.9 & 29 \\
\hline Paz-Ares ${ }^{45}$ & $\begin{array}{l}\text { - Paclitaxel poliglumex } 210 \text { (for PS } 0 \text { or I) or } 175 \\
\text { (for PS 2) dl q3w }\end{array}$ & & 8 & 6.9 & 25 \\
\hline \multirow[t]{2}{*}{ Hanna $^{46}$} & - Doce $75 \mathrm{dl}$ q3ws & 571 & 8.8 & 7.9 & 29.7 \\
\hline & - Pem $500 \mathrm{dl}$ q3w & & 9.1 & 8.3 & 29.7 \\
\hline \multirow[t]{2}{*}{$\mathrm{Camps}^{47}$} & - Doce $75 \mathrm{dl} q 3 \mathrm{w}$ & 259 & 9.3 & 6.6 & 27.0 \\
\hline & - Doce $35 \mathrm{dl} / 8 / 15 / 22 \mathrm{q} 6 \mathrm{w}$ & & 4.8 & 5.4 & 22.0 \\
\hline DISTALOI & - Doce $75 \mathrm{dl} q 3 \mathrm{w}$ & 220 & 2.7 & $29 w$ & 21 \\
\hline Gridellii & - Doce $33.3 \mathrm{dl} / 8 / \mathrm{I} 5 / 22 / 29 / 36 \mathrm{q} 8 \mathrm{w}$ & & 5.5 & $25 w$ & 31 \\
\hline \multirow[t]{2}{*}{ Schuette ${ }^{49}$} & - Doce 75 dl q3w & 215 & 12.6 & 6.3 & 26.9 \\
\hline & - Doce $35 \mathrm{dl} / 8 / 15 \mathrm{q} 4 \mathrm{w}$ & & 10.5 & 9.2 & 39.5 \\
\hline INTEREST & - Doce $75 \mathrm{dl}$ q3w & 1433 & 7.6 & 8.0 & 34 \\
\hline $\mathrm{Kim}^{50}$ & - Gefitinib 250 mg PO daily & & 9.1 & 7.6 & 32 \\
\hline V-15-32 & - Doce $60 \mathrm{dl} \mathrm{q} 3 \mathrm{w}$ & 490 & $12.8^{*}$ & 14.0 & 54 \\
\hline Maruyama $^{51}$ & - Gefitinib 250 mg PO daily & & 22.5 & 11.5 & 48 \\
\hline JCOG0I4 & - Doce $60 \mathrm{dl} / 8 \mathrm{q} 3 \mathrm{w}$ & 130 & 6.8 & 10.1 & 43.1 \\
\hline Takeda $^{53}$ & $\begin{array}{l}\text { - Doce } 60+\text { gem } 800 \mathrm{dl} / 8 \mathrm{q} 3 \mathrm{w} * \text { terminated } \\
\text { early for ILD }\end{array}$ & & 7.0 & 10.3 & 46.0 \\
\hline DISTAL-2 & - Doce $33.3 \mathrm{dl} / 8 / \mathrm{I} 5 \mathrm{q} 4 \mathrm{w}$ & 84 & 6.4 & 40.0 & 0.38 \\
\hline \multirow[t]{2}{*}{ Gebbia $^{54}$} & - Doce $30 \mathrm{dl} / 8 / \mathrm{I} 5$ + gem $800 \mathrm{dl} / 8 \mathrm{q} 4 \mathrm{w}$ & & 16.7 & 32.6 & 0.17 \\
\hline & - Doce $30 \mathrm{dI} / 8 / 15$ + cape 625 BID d5-18 q4w & & 5.3 & 39.7 & 0.39 \\
\hline ZODIAC Herbst ${ }^{58}$ & $\begin{array}{l}\text { - Doce } 75 \mathrm{dl}+\text { vandetanib } 100 \mathrm{mg} \text { PO daily q3w } \\
\text { - Doce } 75 \mathrm{dl}+\text { placebo PO daily } \mathrm{q} 3 \mathrm{w}\end{array}$ & 1391 & $\begin{array}{l}17^{*} \\
10\end{array}$ & \multicolumn{2}{|c|}{$\begin{array}{l}\text { NR, but hazard ratio of } \\
\text { death: } 0.9 \text { I favoring } \\
\text { vandetanib, NS }\end{array}$} \\
\hline \multirow[t]{4}{*}{ Fidias $^{59}$} & Carbo AUC $5 \mathrm{dl}$ and gem $1000 \mathrm{dl} / 8 \mathrm{q} 3 \mathrm{wks} \times 4$, & 566 & & & \\
\hline & then if no PD, randomize to & 153 & 11.7 & 12.3 & 51.1 \\
\hline & - Doce 75 q3w $\times 6$ immediately & 156 & 11.2 & 9.7 & 43.5 \\
\hline & - Doce $75 q 3 w \times 6$ upon progression & & & & \\
\hline
\end{tabular}

Notes: *denotes statistically significant result. All doses in milligrams per meter squared $\left(\mathrm{mg} / \mathrm{m}^{2}\right)$ except as noted.

Abbreviations: N, number of subjects; RR, response rate; MST, median survival time; OS, overall survival; Doce, docetaxel; q3w, every 3 weeks; Vin, vinblastine. Ifos, ifosfamide; PS, performance status; ILD, interstitial lung disease; Gem, gemcitabine; Cape, capecitabine; BID, twice daily; AUC, area under the curve; NR, not reported; NS, nonsignificant; $\mathrm{PD}$, progressive disease.

Kubota and colleagues also demonstrated improved response and survival with cisplatin/docetaxel when compared to a combination of cisplatin and vindesine. ${ }^{23}$

However, two other phase III studies have shown that docetaxel-containing doublets are comparable, although not superior, to other choices. The GLOB-3 study reported by Tan and colleagues showed no significant difference between cisplatin/docetaxel and a combination of cisplatin with both oral and IV vinorelbine..$^{24}$ Finally, another phase III reported by Booton and colleagues compared docetaxel and carboplatin with a triple drug regimen of cisplatin, mitomycin and either ifosfamide or vinblastine, and showed there to be no difference in survival between the arms. ${ }^{25}$
In a large Eastern Cooperative Oncology Group (ECOG) study designed to compare the efficacy of the various "third-generation" chemotherapeutic agents, 1207 patients were randomized to the control arm of cisplatin/paclitaxel or to one of three experimental arms: cisplatin/docetaxel; cisplatin/gemcitabine; and carboplatin/paclitaxel. Schiller and colleagues reported that none of these combinations was superior with respect to survival or response. As a reference point, the cisplatin/docetaxel arm had a median survival time of 7.4 months, compared to 7.9 months median for all enrolled patients. ${ }^{26}$ Overall the results have been mixed with the cisplatin/docetaxel first-line trials, with several showing superiority of this regimen as compared to cisplatin/vinca 
alkaloid, with others showing equivalence of the combination to other platinum doublets.

Aside from the TAX 326 elderly subgroup analysis, some groups have investigated use of platinum doublets specifically in the elderly. Yoshimura and colleagues considered three-weekly carboplatin/docetaxel doses in a phase II trial and showed a $47 \%$ overall response rate, with median progression-free survival (PFS) 4.4 months and survival 9.9 months. ${ }^{27}$ Although weekly docetaxel dosing has been explored more often in the second-line setting as noted below, Han and colleagues did consider a first-line weekly cisplatin/docetaxel doublet in an elderly population over the age of 70 . Less than $10 \%$ of patients had grade 3 neutropenia; with only diarrhea (11\%), neuropathy $(11 \%)$ and stomatitis (11\%) noted at grade 3 intensity in over $10 \%$ of patients. Median survival was 10.9 months, with a median time to progression 5.0 months, suggesting this may be a viable alternative to three-weekly dosing in the elderly. ${ }^{28}$ Similar results were seen in a phase II study by Ohe and colleagues, with a $12 \%$ incidence of grade 3 neutropenia and a median survival of 15.8 months. ${ }^{29}$ Based on these results, the Japanese Cooperative Oncology Group (JCOG) initiated a phase III study for elderly patients comparing docetaxel and cisplatin to docetaxel alone; this study is ongoing.

To investigate an alternative dosing doublet strategy, Miller and colleagues performed a randomized phase II trial of dose-dense docetaxel and cisplatin $\left(75 \mathrm{mg} / \mathrm{m}^{2}\right.$ on day 1 of each 14 day cycle) with or without the putative chemoprotective agent BNP7787. To accomplish this dose-dense strategy, they mandated darbepoetin and pegfilgrastim on day 2 of each cycle. With 160 patients enrolled, they found a response rate of 55\% versus $51 \%$ and median survival of 10.7 versus 14.1 months, with an incidence of only $4 \%$ febrile neutropenia; although neurotoxicity of grade 2 or greater was $31 \%$ and was not improved with the use of BNP7787. ${ }^{30}$ Thus the dose-dense regimen has not been pursued. Another alternative strategy, to use docetaxel sequentially after a nonplatinum doublet, was also evaluated. Kubota and colleagues compared carboplatin and paclitaxel to a strategy of three cycles of vinorelbine/gemcitabine followed by three cycles of docetaxel. Response was significantly better in the carboplatin arm, although there was no difference in survival, and this sequential dosing approach is not under further investigation. ${ }^{31}$

\section{Docetaxel in combination with gemcitabine}

Given the toxicity associated with platinum doublet therapy, there has been interest in evaluating whether a combination of gemcitabine and docetaxel may be comparably effective. Two phase III studies by Georgoulias and colleagues ${ }^{32}$ and Pujol and colleagues ${ }^{33}$ compared docetaxel/gemcitabine with cisplatin/vinorelbine, and yet neither showed a statistically significant difference in response or survival, although a $P$ value of 0.053 in the Georgoulias study suggested a trend in response rate favoring the cisplatin/vinorelbine combination, $39.2 \%$ versus $30.0 \%{ }^{32}$ However both studies showed significantly less neutropenia in the docetaxel arm, even despite the standardized use of growth factor in one of the protocols. ${ }^{32}$ On the other hand, the incidence of significant grade 3 or 4 pneumonitis was prominent in the Pujol protocol, with eight patients (5.2\%) noted to have pneumonitis attributed to the docetaxel/gemcitabine regimen. ${ }^{33}$

Two other phase III studies have assessed whether docetaxel with gemcitabine is superior to docetaxel alone. Georgoulias and colleagues showed significantly improved response and survival with the combination $(26.8 \%$ versus $11.1 \%, P<0.001$ and 9.4 versus 8.3 months, $P=0.037),{ }^{34}$ while Hainsworth and colleagues showed a nonsignificant trend in the same direction among elderly patients over the age of $65 .{ }^{35}$ While both studies showed slightly more neutropenia in the combination arms, neither showed a significant increase in febrile neutropenia.

\section{Docetaxel in a biomarker-driven regimen choice}

Research into the development of prognostic and predictive biomarkers in lung cancer has flourished, and accordingly, there has been interest in prospectively analyzing whether a treatment regimen based on biomarkers can yield superior efficacy. One biomarker of interest is endonuclease excision repair cross-complementing 1 (ERCC1), a DNA repair enzyme involved in the nucleotide excision repair process. High levels of ERCC1 mRNA are predictive of increased resistance to platinum therapy and prognostic for worse survival overall, regardless of treatment. In an innovative phase III study design, the Spanish Lung Cancer Group sought to assess whether personalization of therapy based on ERCC1 would be more effective than a standard choice. The control arm consisted of cisplatin and docetaxel, while patients randomized to the experimental arm received treatment depending on their ERCC1 level; if low, they would receive cisplatin/docetaxel, and if high, they would receive gemcitabine/docetaxel. Response was significantly improved in the arm with the directed therapy, $47 \%$ versus $38 \%, P=0.02$ ), though survival was not significantly improved with a median survival of 9.8 versus 9.9 months, $P=0.59 .{ }^{36}$ 
Expanding further on the idea of the personalization of chemotherapy and given the finding that BRCA1 expression is predictive of a better response to docetaxel and worse response to platinum therapy, the Spanish Lung Cancer Group completed a phase II study that sorted patients based on EGFR and BRCA1 expression. Carriers of an EGFR mutation (either exon 19 deletion or the L858R mutation) received erlotinib, while patients with wild-type EFGR were assessed for BRCA1 mRNA expression levels. Patients with low BRCA1 received gemcitabine/cisplatin, patients with medium BRCA1 received docetaxel/cisplatin, and patients with high BRCA1 received docetaxel alone. While median survival exceeded 28 months in the EGFR mutants, it was: 11 months in the low BRCA1 group; 9 months in the intermediate group; and 11 months in the high group. The investigators also measured RAP80, which modulates the effect of BRCA1, finding that low RAP80 coupled with low BRCA1 would confer a median survival of 26 months. ${ }^{37}$ A phase III study is underway randomizing patients between a standard regimen of cisplatin/docetaxel and a regimen dictated by BRCA1 mRNA levels.

\section{Docetaxel in combination with targeted agents}

Particularly as an "efficacy plateau" appears to have been reached in traditional chemotherapy combinations in NSCLC,${ }^{38}$ there has been greater interest in combining chemotherapy drugs like docetaxel with the newest generation of targeted therapies, with the goal of improving efficacy with manageable toxicity. In an important phase II study, Belani and colleagues added cetuximab, a chimeric epidermal growth factor receptor (EGFR) inhibitor, to a carboplatin/docetaxel doublet, and patients were allowed to continue cetuximab for up to a year as a single agent if there was no progression. Unlike the study noted below, patients were not required to show over-expression of the EGFR. Therapy was well-tolerated, with neutropenia at only $30 \%$ showing greater than $10 \%$ incidence of grade 3 or higher toxicity, and the patients who received single-agent cetuximab found it to be well-tolerated. The overall response rate (ORR) was $15.2 \%$ with medial survival of 10.3 months, suggesting some modest benefit, however; further work on clarifying appropriate patient selection is warranted. ${ }^{38}$

Another phase III study, BMS-099, evaluated carboplatin with docetaxel or paclitaxel at the option of the investigator, randomized to cetuximab or not. The study did not meet its primary endpoint of improvement in centrally reviewed PFS (4.40 versus 4.24 months, $P=0.2358$ ) even though an investigator-determined PFS did favor the cetuximab arm at 4.30 versus 3.78 months $(P=0.0015)$. Interestingly, the response rate, as judged by central review, favored cetuximab as well $(25.7 \%$ versus $17.2 \%, P=0.0066)$, but was not significantly different by investigator review, $26.9 \%$ versus $22.8 \%, P$ value not reported in the abstract). Furthermore, no overall survival benefit was seen with the addition of cetuximab ( 9.7 versus 8.4 months, $P=0.170$ ). ${ }^{39}$

A recent randomized phase II study by Lilenbaum and colleagues evaluated two targeted treatments combined with a docetaxel backbone in patients with ECOG performance status (PS) 2, cetuximab and bortezomib, a proteosome inhibitor. Unfortunately, with a PFS of 3.4 and 1.9 months and median survivals of 5.0 and 3.9 months repectively, the trial did not meet its own prespecified PFS endpoint to justify moving to a phase III trial. ${ }^{40}$

\section{Second-line use of docetaxel in advanced or metastatic NSCLC}

After the failure of a traditional platinum doublet in advanced or metastatic disease, there was no treatment choice with proven efficacy until the introduction of docetaxel. Work has continued apace to clarify the best way to use docetaxel in a patient population that is often typified by declining performance status, with an even greater emphasis on toxicity and quality of life endpoints in addition to survival.

\section{Docetaxel as single agent}

The TAX 317 study established docetaxel as superior to best supportive care with respect to survival, ${ }^{41}$ and also showed that quality of life was improved with active therapy. ${ }^{42}$ The study randomized patients to docetaxel, evenly divided between doses of $75 \mathrm{mg} / \mathrm{m}^{2}$ or $100 \mathrm{mg} / \mathrm{m}^{2}$ on a 3-weekly regimen, versus best supportive care in the control arm. Only the $75 \mathrm{mg} / \mathrm{m}^{2}$ dose was found to improve survival, with a median survival of 7.5 months compared to 4.6 months on best supportive care $(P=0.010)$, though with a median survival on the higher dose arm of 5.9 months. This was thought to reflect some contribution from toxicity, with $85.7 \%$ of patients on the $100 \mathrm{mg} / \mathrm{m}^{2}$ arm experiencing grade 3 or 4 neutropenia compared with $67.3 \%$ on the $75 \mathrm{mg} / \mathrm{m}^{2}$ arm. Notably, 11 patients $(22.4 \%)$ on the $100 \mathrm{mg} / \mathrm{m}^{2}$ arm developed febrile neutropenia, 3 of whom died, as compared with just one case $(1.8 \%)$ of nonfatal febrile neutropenia in the $75 \mathrm{mg} / \mathrm{m}^{2} \mathrm{arm} .{ }^{41}$ The quality of life improvement was demonstrated by a statistically significant difference in a pain scale in patients treated with docetaxel ( $P=0.006)$, with trends toward less fatigue $(P=0.06)$ and weight loss $(P=0.07)$. Additionally significantly less tumor-related medication was used in the docetaxel patients $(P=0.02){ }^{42}$ 
The first phase III trial to show the superiority of docetaxel over another agent was TAX 320, in which docetaxel (at $75 \mathrm{mg} / \mathrm{m}^{2}$ and $100 \mathrm{mg} / \mathrm{m}^{2}$ ) was compared to the investigator's choice of vinorelbine or ifosfamide. Both doses of docetaxel showed greater response, although as in TAX 317, only docetaxel at $75 \mathrm{mg} / \mathrm{m}^{2}$ showed a statistically significant improvement in 1-year survival, from $19 \%$ in the control arm to $32 \%(P=0.025)$, with survival in the $100 \mathrm{mg} / \mathrm{m}^{2}$ group of only $21 \%$. There was again a large difference between grade 4 neutropenia incidence in the two arms, with $77 \%$ of patients treated at $100 \mathrm{mg} / \mathrm{m}^{2}$ versus $54 \%$ treated at $75 \mathrm{mg} / \mathrm{m}^{2}$ developing this toxicity. ${ }^{6}$ Another study by Ramlau and colleagues compared docetaxel to the oral form of topotecan, and found no difference, with respect to response or survival, although there was an improved quality of life in patients treated with docetaxel. ${ }^{43}$

Based on the impressive results in the TAX 317 and TAX 320 trials, docetaxel was approved by the US FDA as a single agent for the second line treatment of NSCLC in 1999, the first drug to receive this indication. ${ }^{44}$ It is still considered a reference second-line regimen.

Docetaxel has also served as the control arm in phase III studies of newer experimental agents. The STELLAR 2 trial compared docetaxel to paclitaxel poliglumex (PPX), a conjugate that links paclitaxel to a polymeric backbone designed to increase permeation and retention of drug intratumorally. However there was no difference in response or survival, and while PPX was associated with less neutropenia and febrile neutropenia, there was a higher incidence of hypersensitivity reaction and neuropathy with PPX, the latter apparently associated with cumulative doses. ${ }^{45}$

Finally, Hanna and colleagues compared docetaxel to pemetrexed in 571 patients, and found no significant difference in response or survival, although there was significantly more neutropenia in the docetaxel arm, suggesting pemetrexed to be the more tolerated agent. ${ }^{46}$ Based on these results, pemetrexed is the only other chemotherapeutic besides docetaxel approved by the US FDA as a second line therapy for NSCLC.

\section{Docetaxel as single agent dosed weekly}

The assessment as to what extent the weekly dosing of docetaxel could reduce toxicity, particularly of febrile neutropenia, and whether efficacy was retained, three phase III studies have compared 3-weekly to weekly dosing. None of the three studies showed significant changes in response or survival, although two trended toward favoring the 3-weekly dosing ${ }^{47,48}$ while one showed a trend in favor of weekly dosing. ${ }^{49}$ All three, however, showed decreased grade 3 and 4 neutropenia with the weekly schedule. Results from these three studies and two additional randomized phase II studies were compiled in a meta-analysis, which analyzed data from 865 patients in total and found overall a non-significant difference in median survival (27.4 weeks in the 3-week dosing versus 26.1 weeks in the weekly dosing, $P=0.245)$, however, as expected, a reduction of grade 3 and 4 neutropenia (18\% versus 5\%) and febrile neutropenia (6\% versus $<1 \%$ ) with weekly dosing (both $P<0.001$ ). ${ }^{10}$ Collectively these results suggest that weekly dosing is an acceptable alternative, particularly in a patient at greater baseline risk for neutropenia, although one must weigh the burden of time and expense of more frequent visits, and the chance of slightly less efficacy when deciding on the dosing regimen for a patient.

\section{Docetaxel as single agent versus targeted therapies}

Two large randomized trials have compared the oral EGFR inhibitor gefitinib to docetaxel. INTEREST, the larger of the two with 1433 patients on 4 continents, was designed to evaluate the noninferiority of gefitinib in the entire study population and superiority among those with a high EGFR copy number. The study met its criteria for noninferiority, achieving a similar response and survival but with considerably less neutropenia for gefitinib treated patients when compared to those receiving docetaxel. However, the subgroup of patients with high a EGFR copy number did not show any improved response or survival with gefitinib. ${ }^{50}$ A Japanese trial, V-15-32, also randomized patients to docetaxel or gefitinib with an endpoint of noninferiority. The endpoint was not met, and there was no statistically significant difference in survival. ${ }^{51}$ Notably, a combined phase I/II trial was designed to study the combination of docetaxel and gefitinib in an elderly population over the age of 70 , however, after 11 of the 26 enrolled patients experienced grade 3-5 nonhematologic toxicity in the first cycle, the study was discontinued..$^{52}$

\section{Docetaxel in combination with chemotherapy}

Docetaxel has been evaluated in combination with gemcitabine for second-line use in two phase III studies. JCOG0104 compared docetaxel given days on 1 and 8 in a 3-weekly cycle both with and without gemcitabine. The study was halted early for excessive incidence of interstitial lung disease in the combination arm, with a $17 \%$ incidence (and three deaths) compared to an incidence of only $2 \%$ 
in the docetaxel arm. At the time of discontinuation there was no difference between the arms in response rate or survival. ${ }^{53}$ In the DISTAL-2 study weekly docetaxel was compared alone versus docetaxel in combination with either gemcitabine or capecitabine; once again, there was no difference among the arms in response or survival. ${ }^{54} \mathrm{~A}$ phase II trial by Schneider and colleagues evaluated the addition of celecoxib to docetaxel in second-line therapy, and yet with a $58 \%$ incidence of grade 3 neutropenia, and 21\% neutropenic fever the study was halted early with a median survival of only 6.9 months. ${ }^{55}$ Thus the concept of chemotherapy doublets as second-line therapy has largely been abandoned.

\section{Docetaxel in combination with targeted therapies}

Combinations of docetaxel with drugs targeting EGFR and other pathways have shown more promise. Kim and colleagues evaluated docetaxel in combination with cetuximab in a phase II trial. Patients had to show an overexpression of EGFR and to have progressed or relapsed within 3 months of the original chemotherapy. Leucopenia and rash were noted in $27 \%$ and $22 \%$ of patients respectively at a grade 3 severity. Response rate was $20 \%$ with a median time to progression of 104 days and survival of 7.5 months, suggesting to the authors that further phase III testing was warranted. ${ }^{56}$

Combining EGFR and vascular endothelial growth factor (VEGF) inhibition in a single oral tyrosine kinase inhibitor, vandetanib, has been one focus of study. Heymach and colleagues reported a randomized phase II trial adding vandetanib or placebo to docetaxel. Though there was no survival benefit noted, the study met its endpoint of prolonged PFS, ie, 18.7 weeks at dose of $100 \mathrm{mg}$ versus 17.0 weeks at a dose of $300 \mathrm{mg}$ versus 12 weeks for docetaxel alone $(P=0.037$ comparing $100 \mathrm{mg}$ dose to placebo). ${ }^{57}$ Preliminary findings from the phase III ZODIAC study have now been reported that also show a statistically significant difference in PFS when vandetanib as compared to placebo was added to docetaxel, 17.3 versus 14.0 weeks (hazard ratio $0.79, P<0.001$ ), though survival was not significantly different with a hazard ratio of 0.91, $(P=0.196$; median survival not reported). These results represent the first time an oral targeted therapy has increased efficacy when added to standard chemotherapy in NSCLC. ${ }^{58}$ However, the lack of a survival benefit may limit further development of this combination.

\section{Docetaxel immediately after first-line treatment versus waiting for progression}

Given the consistent findings of efficacy in second-line treatment, Fidias and colleagues investigated whether it would be advantageous to give docetaxel as consolidation immediately after a full course of a first-line platinum doublet (in this case, carboplatin and gemcitabine) rather than to wait for progression before starting docetaxel. A total of 309 of 566 enrolled patients completed four cycles of the doublet without developing progressive disease and were randomized. There was a trend toward better survival in the early treatment arm, 12.3 versus 9.7 months $(P=0.0853)$. Notably, only 98 out of 156 patients in the delayed arm were able to receive at least one cycle of docetaxel, suggesting that treatment intensity is higher if docetaxel can be given earlier, presumably when patients are more fit. ${ }^{59}$ In a secondary analysis of those patients on the delayed arm who did go on to receive docetaxel, the survival was equivalent to patients on the immediate docetaxel arm.

\section{Use of docetaxel in earlier-stage disease}

Given the proven activity of docetaxel in advanced and metastatic NSCLC, multiple approaches with the agent in earlier stages of disease have been investigated.

\section{Docetaxel for chemoradiation or as consolidation} after chemoradiation in unresectable stage III disease Preclinical data suggest that docetaxel is an effective radiosensitizer in addition to its antitumor properties, and so its use in inoperable locally or regionally advanced NSCLC as part of a regimen that includes radiation therapy has been an important area of study. ${ }^{60}$ However, consensus regarding the best approach for unresectable stage III disease with respect to the order of treatment and the choice of agents remains elusive. A phase II Southwest Oncology Group (SWOG) study in unresectable stage IIIB disease showed an impressive 26-month median survival time with a regimen of chemoradiation (with cisplatin and etoposide) followed by docetaxel consolidation. ${ }^{61}$ This regimen has subsequently been adopted as the SWOG reference standard, and thus serves as a platform for ongoing trials in this patient population. For example, the SWOG S0023 study was a phase III trial of cisplatin/etoposide with radiation, then docetaxel consolidation as a standard, followed by a randomization to gefitinib or placebo. This study was halted early for not meeting a midpoint efficacy criterion, and the final results actually reported a 35 versus 23 month advantage for the placebo arm with respect to survival $(P=0.013){ }^{62}$

In the phase III setting, US Oncology and the Hoosier Oncology Group randomized patients to docetaxel $75 \mathrm{mg} / \mathrm{m}^{2}$ every 3 weeks or observation after definitive chemoradiation 
with cisplatin and etoposide, as in the SWOG reference standard regimen. Unfortunately, the study was terminated early for not exceeding pre-determined futility criteria, and on final review of the data mean survival time MST was 21.2 months in the patients receiving docetaxel versus 23.3 months in the control arm $(P=0.883)$, with $5.5 \%$ deaths classified as premature on account of docetaxel. ${ }^{63}$

Docetaxel has also been studied as part of a combined chemoradiation regimen in locally advanced disease. In the OLCSG 0007 trial, Kiura and colleagues randomized patients to either docetaxel/cisplatin or mitomycin, cisplatin and vindesine, both regimens given concurrently with radiation. The 2-year survival target, the primary endpoint of the study, was significantly better in the docetaxel and cisplatin arm, $60.3 \%$ versus $48.1 \%(P=0.0183)$, with trends toward an improved response rate and 5-year survival. Hematologic toxicities were also significantly less in the arm with docetaxel. ${ }^{64}$

Other groups have used regimens employing docetaxel as part of chemoradiation therapy as either induction or consolidation. Scagliotti and colleagues performed a randomized phase II trial using induction chemotherapy with cisplatin/docetaxel, and then randomized patients to radiation alone or with concurrent weekly docetaxel at $20 \mathrm{mg} / \mathrm{m}^{2}$. ORR was $58 \%$ in the chemoradiation arm compared to $48 \%$ in the radiation arm, with a survival of 14.9 versus 14.0 months suggesting a trend towards improvement, however, this result was not significant, with having overlapping confidence intervals. ${ }^{65}$ Jain and colleagues recently published a phase II trial using weekly carboplatin/docetaxel with radiation, followed by consolidation with carboplatin/docetaxel in stage IIIA or IIIB patients. The regimen was fairly well-tolerated with leucopenia and esophagitis the primary toxicities, although the 1 - and 2-year survival rates were $45 \%$ and $20 \%$ respectively, which did not appear to improve significantly on historical experience. ${ }^{66}$ Thus, while considerable controversy surrounds the appropriate regimen for the treatment of stage III NSCLC, many active options contain docetaxel.

\section{Docetaxel as neoadjuvant therapy in resectable stage III disease}

An international phase III trial was performed by Mattson and colleagues to evaluate docetaxel $\left(100 \mathrm{mg} / \mathrm{m}^{2}\right)$ every 3 weeks for at least three cycles, before local surgery or radiation, with a curative intent in radically resectable stage III patients versus no neoadjuvant therapy. There was no statistically significant difference between the arms despite a $28 \%$ response rate in the docetaxel arm; although there was a trend toward improved survival (14.8 versus 12.6 months). ${ }^{67,68}$
Although docetaxel alone in the neoadjuvant setting was not shown to be particularly efficacious there has been some promising data in phase II trials evaluating docetaxel in combination with cisplatin or carboplatin in this setting. ${ }^{69}$ However, these findings have yet to be replicated in a large randomized study.

\section{Docetaxel as neoadjuvant or adjuvant therapy in stage IB through III disease}

A recent randomized phase II study by Kunitoh and colleagues investigated the use of docetaxel with or without cisplatin as neoadjuvant therapy before surgery in clinical stage IB and II patients. The response rate and compete resection rates were higher in the arm with docetaxel/platinum ( $45 \%$ versus $15 \%$ and $95 \%$ versus $87 \%$ respectively), and the 1 -year survival, the primary endpoint, was good at $78 \%$ and $62 \%$ respectively, suggesting that further study is warranted in this clinical setting. ${ }^{70}$

Other investigators have considered adjuvant docetaxel in phase II studies. Kawamura and colleagues evaluated a docetaxel/gemcitabine doublet for adjuvant use in stage IIA-IIIA NSCLC. Three of the first 21 patients experienced interstitial lung disease ILD, so the gemcitabine was decreased in dose from 1000 to $800 \mathrm{mg} / \mathrm{m}^{2}$ for the duration of the study. Twenty-nine of 35 patients completed at least three cycles of therapy. The 4-year survival rate was $65.8 \%$, with $42.9 \%$ recurrence-free survival. ${ }^{71}$ In another phase II study, Stinchcombe and colleagues administered carboplatin and docetaxel in an adjuvant setting to patients with curatively resected NSCLC. Among the 72 patients: $40 \%$ were stage I; $36 \%$ were stage II; $22 \%$ were stage IIIA; and $1 \%$ were stage IIIB. This was designed as a feasibility study and $79 \%$ of patients were able to receive four cycles of treatment with acceptable toxicity. However, the efficacy results have yet to be reported. ${ }^{72}$ Azzoli and colleagues, meanwhile, evaluated the feasibility of a cisplatin/docetaxel doublet in stage I-III disease, finding that 5 of 16 patients were unable to complete three cycles of weekly docetaxel with cisplatin, as compared to 6 of 11 unable to complete 3 -weekly dosing of both medications. ${ }^{73}$

\section{Quality of life and other patient-reported outcomes}

Along with other areas of oncology, the field of lung cancer research has come to recognize the importance of assessing patient-reported outcomes, and this is reflected in their inclusion in many of the trials detailed above. Particularly in advanced NSCLC; when treatment with curative intent is 
not feasible and one regimen may confer only a small incremental survival benefit compared to another regimen, it is important to consider how the toxicities of the regimens affect the quality of life of patients. Such differences can influence regulatory approval decisions about a drug, and just as importantly, can impact an individual treatment decision made in the clinic. Aside from assessing toxicity directly with common terminology criteria for adverse events (CTCAE) criteria, there are at least three validated measures in lung cancer to help assess how toxicity, as well as other factors, impact a patient's quality of life. These include the lung cancer symptom scale (LCSS), the EORTC lung cancer module, and the functional assessment of cancer therapy - lung (FACT-L). ${ }^{74}$

An example of how patient-reported outcomes can complement traditional endpoints of response and survival is seen in the pivotal trial published by Roszkowski and colleagues comparing docetaxel with best supportive care and that described above. ${ }^{18}$ Though the survival difference was statistically significant, the increment was only 0.3 months (6.0 versus 5.7 months) which may not be considered clinically relevant by all patients or practitioners. However, when informed by quality of life data collected prospectively, alongside survival data that showed an improvement in patient-reported pain, the difference between the two approaches becomes more meaningful. ${ }^{75}$

\section{Future directions}

Large phase III trials are now underway that use docetaxel as a standard therapeutic backbone for all patients, who are then additionally randomized to a novel drug versus placebo. Some novel drug examples include:

- ASA 404, a small molecule vascular disrupting agent;

- BIBF 1120, a novel inhibitor of VEGF, platelet-derived growth factor receptor (PDGFR) and fibroblast growth factor receptor (FGFR), targeting angiogenesis;

- Cetuximab, an EGFR inhibitor;

- Enoxaparin, a low-molecular-weight heparin;

- Tavocept, a chemoprotective agent that may reduce the incidence of neurotoxicity in taxane and platinum agents, while allowing greater dose intensity;

Many novel agents are also being assessed in a phase II setting in combination with docetaxel, including sunitinib, sorafenib, bortezimib, AZD6244 (a MEK inhibitor), PR104 (a hypoxia-induced alkylating agent), nimotuzumab (an EGFR inhibitor), apricoxib (a COX-2 inhibitor), and MGCD265 (a multitargeted tyrosine kinase inhibitor, including c-MET), among others.
Aside from novel agents, adaptive use of docetaxel based on predictive biomarkers is being considered. The Spanish Lung Cancer Group is using BRCA1 to select treatments in the experimental arm, while a phase III SWOG study uses RRM1 and ERCC1, with docetaxel given to patients with high RRM1, indicative of resistance to gemcitabine.

Docetaxel-based platinum doublets are also used in ongoing studies enrolling patients in earlier stages of the disease. For example, in the adjuvant trial ECOG E1505 exploring the addition of bevacizumab to adjuvant chemotherapy for patients with resected stage IB through IIIA disease, cisplatin/docetaxel is one of the four backbone regimens. In CALGB 20506, designed to assess the utility of a genomic prognostic model to identify stage I patients who would benefit from adjuvant chemotherapy, cisplatin/ docetaxel is one of the three options for patients randomized to treatment rather than observation.

\section{Conclusions}

The advent of docetaxel as the first effective drug for use in advanced and metastatic NSCLC after progression on a platinum doublet was an important milestone, offering renewed hope in a morbid disease state. Unfortunately there has been somewhat of a plateau in efficacy with chemotherapeutic agents; however, as the molecular biology of NSCLC has been further elucidated over the past decade there is hope that targeted therapies may yield improved results, with tolerable toxicity profiles, in appropriately chosen patients. Even as new compounds and novel regimens are developed, docetaxel will continue to play an important role in the treatment of NSCLC, both as a backbone for new regimens, and as the current standard of care in the both the first-line setting as part of a platinum doublet, and as a single agent for second-line therapy. Important work continues to evaluate how to identify a priori which patients will most benefit from docetaxel, based on clinical characteristics and biomarkers.

\section{Disclosures}

The authors report no conflicts of interest relevant to this research.

\section{References}

1. Jemal A, Siegel R, Ward E, et al. Cancer statistics, 2009. CA Cancer J Clin. 2009;59(4):225-249.

2. Molina JR, Yang P, Cassivi SD, et al. Non-small cell lung cancer: epidemiology, risk factors, treatment, and survivorship. Mayo Clin Proc. 2008;83(5):584-594.

3. Cortes JE, Pazdur R, Cortes JE, Pazdur R. Docetaxel. J Clin Oncol. 1995;13(10):2643-2655. 
4. Verweij J, Clavel M, Chevalier B. Paclitaxel (Taxol) and docetaxel (Taxotere): not simply two of a kind. Ann Oncol. 1994;5(6):495-505.

5. Montero A, Fossella F, Hortobagyi G, et al. Docetaxel for treatment of solid tumours: a systematic review of clinical data. Lancet Oncol. 2005;6(4):229-239.

6. Fossella FV, DeVore R, Kerr RN, et al. Randomized phase III trial of docetaxel versus vinorelbine or ifosfamide in patients with advanced non-small-cell lung cancer previously treated with platinum-containing chemotherapy regimens. The TAX 320 Non-Small Cell Lung Cancer Study Group. [erratum appears in J Clin Oncol. 2004;22(1):209]. J Clin Oncol. 2000;18(12):2354-2362.

7. Herbst RS, Khuri FR, Herbst RS, Khuri FR. Mode of action of docetaxel - a basis for combination with novel anticancer agents. Cancer Treat Rev. 2003;29(5):407-415.

8. Fitzpatrick FA, Wheeler R, Fitzpatrick FA, Wheeler R. The immunopharmacology of paclitaxel (Taxol), docetaxel (Taxotere), and related agents. Int Immunopharmacol. 2003;3(13-14): 1699-1714.

9. Wailoo A, Sutton A, Morgan A, Wailoo A, Sutton A, Morgan A. The risk of febrile neutropenia in patients with non-small-cell lung cancer treated with docetaxel: a systematic review and meta-analysis. Br J Cancer. 2009;100(3):436-441.

10. Di Maio M, Perrone F, Chiodini P, et al. Individual patient data metaanalysis of docetaxel administered once every 3 weeks compared with once every week second-line treatment of advanced non-small-cell lung cancer. J Clin Oncol. 2007;25(11):1377-1382.

11. Kintzel PE, Michaud LB, Lange MK, Kintzel PE, Michaud LB, Lange MK. Docetaxel-associated epiphora. Pharmacotherapy. 2006;26(6):853-867.

12. Engels FK, Mathot RA, Verweij J, Engels FK, Mathot RAA, Verweij J. Alternative drug formulations of docetaxel: a review. Anti Cancer Drugs. 2007;18(2):95-103.

13. Grande C, Villanueva MJ, Huidobro G, et al. Docetaxel-induced interstitial pneumonitis following non-small-cell lung cancer treatment. Clin Transl Oncol. 2007;9(9):578-581.

14. Nicolopoulos J, Howard A, Nicolopoulos J, Howard A. Docetaxelinduced nail dystrophy. Aust J Derm. 2002;43(4):293-296.

15. Baker SD, Sparreboom A, Verweij J, Baker SD, Sparreboom A, Verweij J. Clinical pharmacokinetics of docetaxel: recent developments. Clin Pharmacokinet. 2006;45(3):235-252.

16. Clarke SJ, Rivory LP, Clarke SJ, Rivory LP. Clinical pharmacokinetics of docetaxel. Clin Pharmacokinet. 1999;36(2):99-114.

17. Azzoli CG, Baker SD, Temin S, et al. American Society of Clinical Oncology clinical practice guideline update on chemotherapy for stage iv non-small-cell lung cancer. J Clin Oncol. 2009;27(36): 6251-6266.

18. Roszkowski K, Pluzanska A, Krzakowski M, et al. A multicenter, randomized, phase III study of docetaxel plus best supportive care versus best supportive care in chemotherapy-naive patients with metastatic or non-resectable localized non-small cell lung cancer (NSCLC). Lung Cancer. 2000;27(3):145-157.

19. Kudoh S, Takeda K, Nakagawa K, et al. Phase III study of docetaxel compared with vinorelbine in elderly patients with advanced non-smallcell lung cancer: results of the West Japan Thoracic Oncology Group Trial (WJTOG 9904). J Clin Oncol. 2006;24(22):3657-3663.

20. Georgoulias V, Ardavanis A, Agelidou A, et al. Docetaxel versus docetaxel plus cisplatin as front-line treatment of patients with advanced non-small-cell lung cancer: a randomized, multicenter phase III trial. J Clin Oncol. 2004;22(13):2602-2609.

21. Fossella F, Pereira JR, von Pawel J, et al. Randomized, multinational, phase III study of docetaxel plus platinum combinations versus vinorelbine plus cisplatin for advanced non-small-cell lung cancer: the TAX 326 study group. J Clin Oncol. 2003;21(16):3016-3024.

22. Belani CP, Fossella F, Belani CP, Fossella F. Elderly subgroup analysis of a randomized phase III study of docetaxel plus platinum combinations versus vinorelbine plus cisplatin for first-line treatment of advanced nonsmall cell lung carcinoma (TAX 326). Cancer. 2005;104(12):2766-2774.
23. Kubota K, Watanabe K, Kunitoh H, et al. Phase III randomized trial of docetaxel plus cisplatin versus vindesine plus cisplatin in patients with stage IV non-small-cell lung cancer: the Japanese Taxotere Lung Cancer Study Group. J Clin Oncol. 2004;22(2):254-261.

24. Tan EH, Rolski J, Grodzki T, et al. Global Lung Oncology Branch trial 3 (GLOB3): final results of a randomised multinational phase III study alternating oral and i.v. vinorelbine plus cisplatin versus docetaxel plus cisplatin as first-line treatment of advanced non-small-cell lung cancer. Ann Oncol. 2009;20(7):1249-1256.

25. Booton R, Lorigan P, Anderson H, et al. A phase III trial of docetaxel/ carboplatin versus mitomycin $\mathrm{C} /$ ifosfamide/cisplatin (MIC) or mitomycin C/vinblastine/cisplatin (MVP) in patients with advanced non-small-cell lung cancer: a randomised multicentre trial of the British Thoracic Oncology Group (BTOG1). Ann Oncol. 2006;17(7): 1111-1119.

26. Schiller JH, Harrington D, Belani CP, et al. Comparison of four chemotherapy regimens for advanced non-small-cell lung cancer. N Engl J Med. 2002;346(2):92-98.

27. Yoshimura N, Kudoh S, Kimura T, et al. Phase II study of docetaxel and carboplatin in elderly patients with advanced non-small cell lung cancer. J Thoracic Oncol. 2009;4(3):371-375.

28. Han K, Cao W, Che J, et al. First line chemotherapy with weekly docetaxel and cisplatin in elderly patients with advanced non-small cell lung cancer: a multicenter phase II study. J Thoracic Oncol. 2009;4(4):512-517.

29. Ohe Y, Niho S, Kakinuma R, et al. A phase II study of cisplatin and docetaxel administered as three consecutive weekly infusions for advanced non-small-cell lung cancer in elderly patients. Ann Oncol. 2004;15(1):45-50.

30. Miller AA, Wang XF, Gu L, et al. Phase II randomized study of dose-dense docetaxel and cisplatin every 2 weeks with pegfilgrastim and darbepoetin alfa with and without the chemoprotector BNP7787 in patients with advanced non-small cell lung cancer (CALGB 30303). J Thoracic Oncol. 2008;3(10):1159-1165.

31. Kubota K, Kawahara M, Ogawara M, et al. Vinorelbine plus gemcitabine followed by docetaxel versus carboplatin plus paclitaxel in patients with advanced non-small-cell lung cancer: a randomised, open-label, phase III study.[see comment]. Lancet Oncol. 2008;9(12): $1135-1142$.

32. Georgoulias V, Ardavanis A, Tsiafaki X, et al. Vinorelbine plus cisplatin versus docetaxel plus gemcitabine in advanced non-small-cell lung cancer: a phase III randomized trial. J Clin Oncol. 2005;23(13): 2937-2945.

33. Pujol JL, Breton JL, Gervais R, et al. Gemcitabine-docetaxel versus cisplatin-vinorelbine in advanced or metastatic non-small-cell lung cancer: a phase III study addressing the case for cisplatin. Ann Oncol. 2005; 16(4):602-610.

34. Georgoulias V, Androulakis N, Kotsakis A, et al. Docetaxel versus docetaxel plus gemcitabine as front-line treatment of patients with advanced non-small cell lung cancer: a randomized, multicenter phase III trial. Lung Cancer. 2008;59(1):57-63.

35. Hainsworth JD, Spigel DR, Farley C, et al. Weekly docetaxel versus docetaxel/gemcitabine in the treatment of elderly or poor performance status patients with advanced nonsmall cell lung cancer: a randomized phase 3 trial of the Minnie Pearl Cancer Research Network. Cancer. 2007;110(9):2027-2034.

36. Cobo M, Isla D, Massuti B, et al. Customizing cisplatin based on quantitative excision repair cross-complementing 1 mRNA expression: a phase III trial in non-small-cell lung cancer. J Clin Oncol. 2007;25(19):2747-2754.

37. Rosell R, Perez-Roca L, Sanchez JJ, et al. Customized treatment in non-small-cell lung cancer based on EGFR mutations and BRCA1 mRNA expression. PLoS One. 2009;4(5):e5133.

38. Belani CP, Schreeder MT, Steis RG, et al. Cetuximab in combination with carboplatin and docetaxel for patients with metastatic or advancedstage nonsmall cell lung cancer: a multicenter phase 2 study. Cancer. 2008;113(9):2512-2517. 
39. Lynch T, Patel T, Dreisbach L, et al. A randomized multicenter phase III study of cetuximab (ErbituxR) in combination with taxane/carboplatin versus taxane/carboplatin alone as first-line treatment for patients with advanced/metastatic non-small cell lung cancer (NSCLC): BMS 099. Paper presented at: IASLC World Conference on Lung Cancer, 2007; Seoul.

40. Lilenbaum R, Wang X, Gu L, et al. Randomized phase II trial of docetaxel plus cetuximab or docetaxel plus bortezomib in patients with advanced non-small-cell lung cancer and a performance status of 2: CALGB 30402. J Clin Oncol. 2009;27(27):4487-4491.

41. Shepherd FA, Dancey J, Ramlau R, et al. Prospective randomized trial of docetaxel versus best supportive care in patients with non-small-cell lung cancer previously treated with platinum-based chemotherapy. J Clin Oncol. 2000;18(10):2095-2103.

42. Shepherd FA, Fossella FV, Lynch T, et al. Docetaxel (Taxotere) shows survival and quality-of-life benefits in the second-line treatment of nonsmall cell lung cancer: a review of two phase III trials. Semin Oncol. 2001;28(1 Suppl 2):4-9.

43. Ramlau R, Gervais R, Krzakowski M, et al. Phase III study comparing oral topotecan to intravenous docetaxel in patients with pretreated advanced non-small-cell lung cancer. J Clin Oncol. 2006;24(18): 2800-2807.

44. Hann CL, Brahmer JR, Hann CL, Brahmer JR. Second-line therapy for advanced non-small-cell lung cancer. Curr Oncol Rep. 2006;8(4): 243-247.

45. Paz-Ares L, Ross H, O’Brien M, et al. Phase III trial comparing paclitaxel poliglumex vs docetaxel in the second-line treatment of non-small-cell lung cancer. Br J Cancer. 2008;98(10): 1608-1613.

46. Hanna N, Shepherd FA, Fossella FV, et al. Randomized phase III trial of pemetrexed versus docetaxel in patients with non-small-cell lung cancer previously treated with chemotherapy. J Clin Oncol. 2004;22(9):1589-1597.

47. Camps C, Massuti B, Jimenez A, et al. Randomized phase III study of 3-weekly versus weekly docetaxel in pretreated advanced non-smallcell lung cancer: a Spanish Lung Cancer Group trial. Ann Oncol. 2006;17(3):467-472.

48. Gridelli C, Gallo C, Di Maio M, et al. A randomised clinical trial of two docetaxel regimens (weekly vs 3 week) in the second-line treatment of non-small-cell lung cancer. The DISTAL 01 study. Br J Cancer. 2004;91(12):1996-2004.

49. Schuette W, Nagel S, Blankenburg T, et al. Phase III study of secondline chemotherapy for advanced non-small-cell lung cancer with weekly compared with 3-weekly docetaxel. J Clin Oncol. 2005;23(33): 8389-8395.

50. Kim ES, Hirsh V, Mok T, et al. Gefitinib versus docetaxel in previously treated non-small-cell lung cancer (INTEREST): a randomised phase III trial. Lancet. 2008;372(9652):1809-1818.

51. Maruyama R, Nishiwaki Y, Tamura T, et al. Phase III study, V-15-32, of gefitinib versus docetaxel in previously treated Japanese patients with non-small-cell lung cancer. J Clin Oncol. 2008;26(26): 4244-4252.

52. Stinchcombe TE, Buzkova P, Choksi J, et al. A phase I/II trial of weekly docetaxel and gefitinib in elderly patients with stage IIIB/IV non-small cell lung cancer. Lung Cancer. 2006;52(3):305-311.

53. Takeda K, Negoro S, Tamura T, et al. Phase III trial of docetaxel plus gemcitabine versus docetaxel in second-line treatment for non-smallcell lung cancer: results of a Japan Clinical Oncology Group trial (JCOG0104). Ann Oncol. 2009;20(5):835-841.

54. Gebbia V, Gridelli C, Verusio C, et al. Weekly docetaxel vs docetaxelbased combination chemotherapy as second-line treatment of advanced non-small-cell lung cancer patients. The DISTAL-2 randomized trial. Lung Cancer. 2009;63(2):251-258.

55. Schneider BJ, Kalemkerian GP, Kraut MJ, et al. Phase II study of celecoxib and docetaxel in non-small cell lung cancer (NSCLC) patients with progression after platinum-based therapy. $J$ Thoracic Oncol. 2008;3(12):1454-1459.
56. Kim ES, Mauer AM, William WN Jr, et al. A phase 2 study of cetuximab in combination with docetaxel in chemotherapy-refractory/ resistant patients with advanced nonsmall cell lung cancer. Cancer. 2009;115(8):1713-1722.

57. Heymach JV, Johnson BE, Prager D, et al. Randomized, placebocontrolled phase II study of vandetanib plus docetaxel in previously treated non small-cell lung cancer. [erratum appears in J Clin Oncol. 2008;26(1):165-166]. J Clin Oncol. 2007;25(27):4270-4277.

58. Herbst RS, Sun Y, Korfee S, et al. Vandetanib plus docetaxel versus docetaxel as second-line treatment for patients with advanced non-small cell lung cancer (NSCLC): A randomized, double-bline phase III trial (ZODIAC). J Clin Oncol. 2009;27(Suppl 18):CRA8003.

59. Fidias PM, Dakhil SR, Lyss AP, et al. Phase III study of immediate compared with delayed docetaxel after front-line therapy with gemcitabine plus carboplatin in advanced non-small-cell lung cancer. J Clin Oncol. 2009;27(4):591-598.

60. Scagliotti GV, Douillard JY, Scagliotti GV, Douillard JY. Docetaxel in combined-modality treatment of inoperable locally or regionally advanced lung cancer. Lung Cancer. 2004;46(Suppl 2):S13-S21.

61. Gandara DR, Chansky K, Albain KS, et al. Long-term survival with concurrent chemoradiation therapy followed by consolidation docetaxel in stage IIIB non-small-cell lung cancer: a phase II Southwest Oncology Group Study (S9504). Clin Lung Cancer. 2006;8(2): 116-121.

62. Kelly K, Chansky K, Gaspar LE, et al. Phase III trial of maintenance gefitinib or placebo after concurrent chemoradiotherapy and docetaxel consolidation in inoperable stage III non-small-cell lung cancer: SWOG S0023. J Clin Oncol. 2008;26(15):2450-2456.

63. Hanna N, Neubauer M, Yiannoutsos C, et al. Phase III study of cisplatin, etoposide, and concurrent chest radiation with or without consolidation docetaxel in patients with inoperable stage III non-small-cell lung cancer: the Hoosier Oncology Group and US Oncology. J Clin Oncol. 2008;26(35):5755-5760.

64. Kiura K, Takigawa N, Segawa Y, et al. Randomized phase III trial of docetaxel and cisplatin combination chemotherapy versus mitomycin, vindesine, and cisplatin combination chemotherapy with concurrent thoracic radiation therapy for locally advanced non-small-cell lung cancer: OLCSG 0007. J Clin Oncol (Meeting Abstracts). 2008;26:7515.

65. Scagliotti GV, Szczesna A, Ramlau R, et al. Docetaxel-based induction therapy prior to radiotherapy with or without docetaxel for non-smallcell lung cancer. Br J Cancer. 2006;94(10):1375-1382.

66. Jain AK, Hughes RS, Sandler AB, et al. A phase II study of concurrent chemoradiation with weekly docetaxel, carboplatin, and radiation therapy followed by consolidation chemotherapy with docetaxel and carboplatin for locally advanced inoperable non-small cell lung cancer (NSCLC). J Thoracic Oncol. 2009;4(6): $722-727$.

67. Mattson K, Abratt R, Ten GV, et al. Docetaxel as neo-adjuvant therapy for radically treatable stage III non-small cell lung cancer: early results of an international phase III study. Lung Cancer. 2001;34(Suppl 4): $\mathrm{S} 21-\mathrm{S} 23$.

68. Mattson KV, Abratt RP, ten Velde G, et al. Docetaxel as neoadjuvant therapy for radically treatable stage III non-small-cell lung cancer: a multinational randomised phase III study. Ann Oncol. 2003;14(1): 116-122.

69. Betticher DC, Rosell R. Neoadjuvant treatment of early-stage resectable non-small-cell lung cancer. Lung Cancer. 2004;46(Suppl 2):S23-S32.

70. Kunitoh H, Kato H, Tsuboi M, et al. A randomised phase II trial of preoperative chemotherapy of cisplatin-docetaxel or docetaxel alone for clinical stage IB/II non-small-cell lung cancer results of a Japan Clinical Oncology Group trial (JCOG 0204). Br J Cancer. 2008;99(6): $852-857$.

71. Kawamura M, Eguchi K, Izumi Y, et al. Phase II trial of gemcitabine and docetaxel in patients with completely resected stage IIA-IIIA nonsmall-cell lung cancer. Cancer Chemother Pharmacol. 2007;60(4): 495-501. 
72. Stinchcombe TE, Harper HD, Hensing TA, et al. The feasibility of adjuvant carboplatin and docetaxel in patients with curatively resected non-small cell lung cancer. $J$ Thoracic Oncol. 2008;3(2):145-151.

73. Azzoli CG, Krug LM, Miller VA, et al. A phase II tolerability study of cisplatin plus docetaxel as adjuvant chemotherapy for resected nonsmall cell lung cancer. J Thoracic Oncol. 2007;2(7):638-644.

74. Gralla RJ, Griesinger F. Interpreting clinical trials in lung cancer: impact of methodology and endpoints. J Thorac Oncol. 2007;2(Suppl 2): S51-S58.
75. Dancey J, Shepherd FA, Gralla RJ, et al. Quality of life assessment of second-line docetaxel versus best supportive care in patients with non-small-cell lung cancer previously treated with platinum-based chemotherapy: results of a prospective, randomized phase III trial. Lung Cancer. 2004;43(2):183-194.

\section{Publish your work in this journal}

Lung Cancer: Targets and Therapy is an international, peer-reviewed, open access journal focusing on lung cancer research, identification of therapeutic targets and the optimal use of preventative and integrated treatment interventions to achieve improved outcomes, enhanced survival and quality of life for the cancer patient. Specific topics covered in the journal include:
Epidemiology, detection and screening; Cellular research and biomarkers; Identification of biotargets and agents with novel mechanisms of action; Optimal clinical use of existing anticancer agents, including combination therapies; Radiation and surgery; Palliative care; Patient adherence, quality of life, satisfaction; Health economic evaluations. 